\title{
Spinal $\mu$-Opioid Receptor-Expressing Dorsal Horn Neurons: Role in Nociception and Morphine Antinociception
}

\author{
Robert H. Kline IV ${ }^{1,3}$ and Ronald G. Wiley ${ }^{1,2,3,4}$ \\ ${ }^{1}$ Laboratory of Experimental Neurology and ${ }^{2}$ Neurology Service Veterans Affairs, Tennessee Valley Healthcare System, Nashville, Tennessee 37212-2637, \\ and Departments of ${ }^{3}$ Neurology and ${ }^{4}$ Pharmacology, Vanderbilt University School of Medicine, Nashville, Tennessee 37212
}

The role of spinal cord $\mu$-opioid receptor (MOR)-expressing dorsal horn neurons in nociception and morphine analgesia is incompletely understood. Using intrathecal dermorphin-saporin (Derm-sap) to selectively destroy MOR-expressing dorsal horn neurons, we sought to determine the role of these neurons in (1) normal baseline reflex nocifensive responses to noxious thermal stimulation (hotplate, tail flick) and to persistent noxious chemical stimulation (formalin) and (2) the antinociceptive activity of intrathecal and systemic morphine in the same tests. Lumbar intrathecal Derm-sap (500 ng) produced (1) partial loss of lamina II MOR-expressing dorsal horn neurons, (2) no effect on MOR-expressing dorsal root ganglion neurons, and (3) no change in baseline tail-flick and hotplate reflex nocifensive responses. Derm-sap treatment attenuated the antinociceptive action of both intrathecal and systemic morphine on hotplate responses. Derm-sap treatment had two effects in the formalin test: (1) increased baseline nocifensive responding and (2) reduced antinociceptive action of systemic morphine. We conclude that MOR-expressing dorsal horn neurons (1) are not essential for determining nocifensive reflex responsiveness to noxious thermal stimuli, (2) are necessary for full antinociceptive action of morphine (intrathecal or systemic) in these tests, and (3) play a significant role in the endogenous modulation of reflex nocifensive responses to persistent pain in the formalin test. Thus, one would predict that altering the activity of MOR-expressing dorsal horn neurons would be antinociceptive and of interest in the search for new approaches to management of chronic pain.

Key words: dermorphin; saporin; $\mu$-opioid receptor; intrathecal morphine; pain; reflex modulation; molecular neurosurgery

\section{Introduction}

Systemic and intrathecal opioids are widely used and highly effective in attenuating clinical pain in humans and nociceptive behavior in animals. In the spinal cord dorsal horn, the G-protein-coupled $\mu$-opioid receptor (MOR) is expressed presynaptically on terminals of nociceptive primary afferent neurons and postsynaptically on neurons in laminas I and II of the dorsal horn (Moriwaki et al., 1996). These laminas receive input from both $\mathrm{A}-\delta$ and $\mathrm{C}$ primary afferent nociceptors (Light and Perl, 1979). Multiple presynaptic and postsynaptic inhibitory mechanisms have been implicated in opioid analgesia and antinociception including voltage-gated calcium channel inhibition, voltagegated potassium channel inhibition, and G-protein-gated inward rectifying potassium (GIRK) channel activation (Hernandez et al., 1993; Marker et al., 2006). However, the precise site(s) and mechanism(s) by which opiate drugs suppress pain in humans and nocifensive responses in animals are areas of active investigation and some uncertainty.

Conjugation of dermorphin, a $\mu$-opioid peptide with high

Received Sept. 28, 2007; revised Dec. 11, 2007; accepted Dec. 11, 2007.

This work was supported by the Department of Veterans Affairs and National Institutes of Health Grant R21-DA14380.

R.G.W. declares competing financial interests.

Correspondence should be addressed to Dr. Ronald G. Wiley, Departments of Neurology and Pharmacology, Vanderbilt University School of Medicine, 1310 24th Avenue South, Nashville, TN 37212. E-mail: ronald.wiley@vanderbilt.edu.

DOI:10.1523/JNEUROSCI.4452-07.2008

Copyright $\odot 2008$ Society for Neuroscience $\quad 0270-6474 / 08 / 280904-10 \$ 15.00 / 0$ affinity and specificity for MOR (Stevens and Yaksh, 1986), to the ribosome inactivating protein saporin creates a targeted toxin (Derm-sap) specific for neurons expressing MOR. Specificity of Derm-sap for cells expressing MOR has been demonstrated pharmacologically by preventing Derm-sap effect in the rostral ventromedial medulla with $\beta$-funaltrexamine, a long-acting MOR antagonist (Porreca et al., 2001). Lumbar intrathecal Derm-sap has been reported not to alter peptidergic or nonpeptidergic afferent terminal staining in the dorsal horn (Zhang et al., 2005) and to spare neurons that do not express MOR (Wiley and Lappi, 2003). We propose that lumbar intrathecal injection of Derm-sap can be used to selectively destroy dorsal horn neurons expressing MOR and that nociceptive testing of Derm-sap-injected rats will reflect the role(s) of lamina II MOR-expressing neurons in nociception and in the antinociceptive action of morphine.

Morphine antinociception is often evaluated using innate reflex responses to high-intensity phasic thermal stimulation (tail flick, paw withdrawal). These methods are problematic for investigation of morphine, because high-intensity thermal stimuli elicit responses that correlate with excitation of $\mathrm{A}-\delta$ nociceptors (Vierck et al., 2002) that are relatively resistant to attenuation by morphine (Lu et al., 1997). Phasic thermal pain in humans and thermal operant escape responses in animals to lower-intensity thermal stimuli produce sensations and nocifensive responses dominated by input from unmyelinated $\mathrm{C}$ nociceptors (Yeomans and Proudfit, 1996) that are highly sensitive to attenuation by systemic morphine (Cooper et al., 1986; Yeomans et al., 1996). C 
nociceptors are preferentially activated by lower-intensity stimuli, $43-45^{\circ} \mathrm{C}$ (Vierck et al. 2004). The present study seeks to determine whether selectively destroying dorsal horn MORexpressing neurons differentially alters morphine effects on nocifensive reflex responses to preferential activation of $\mathrm{C}$ thermal nociceptors $\left(44^{\circ} \mathrm{C}\right)$ versus $\mathrm{A}-\delta$ thermal nociceptor activation $\left(52^{\circ} \mathrm{C}\right)$. Last, the effects of Derm-sap lesions were studied in the formalin test to assess effects on nocifensive reflex responses and morphine action with an entirely different noxious stimulus.

\section{Materials and Methods}

Subjects. With $12 \mathrm{~h}$ light/dark cycles and ad libitum access to food and water, a total of 52 adult female Long-Evans hooded and 16 male Sprague Dawley albino rats weighing 300-450 g (Harlan Industries, Indianapolis, IN) were used and housed two to a shoebox cage, or one to a cage when chronically implanted with lumbar intrathecal catheters. One group of Sprague Dawley male rats was used for Derm-sap/PBS $(n=16)$, baseline hotplate (days 7-21 after toxin) (see Fig. 2), systemic morphine (days 21-38) (see Fig. 5), tail-flick (days 39-40) (see Fig. 2), and terminal formalin ( 3 months) (see Fig. $8 \mathrm{~A}$ ) testing. Group I female rats were used for Derm-sap, baseline hotplate (days -15 to -11 ), intrathecal morphine (days -4 to $8-11$ ) (see Fig. 3 ), and terminal formalin (1 month) (see Fig. $8 B$ ) testing. Group II female rats were used for Derm-sap $(n=$ 7 ), baseline hotplate (days 2-20), systemic morphine/loperamide (days 24-27) (see Fig. 6), and terminal formalin (1 month) (see Fig. 8 B) testing. Group III female rats were used for Derm-sap/PBS $(n=12)$, baseline hotplate (days 2-10), intrathecal morphine (days 9-11) (see Fig. 4), and terminal formalin with or without morphine (1 month) (see Fig. 9) testing. Group IV female rats were used for blank-saporin/PBS $(n=6)$, baseline hotplate (days 7-10), and systemic morphine (days 12-13) testing. Group V female rats were used for unconjugated saporin $(n=6$, three naive) and dorsal horn MOR staining (2 months). Group VI female rats $(n=5)$ were used for control hotplate comparison with catheterized rats.

Female rats were used for MOR1, MOR1C, and GIRK2 staining of controls and Derm-sap-injected spinal cords. The anatomical effect of Derm-sap in the lumbar spinal dorsal horn after $14 \mathrm{~d}$ in male rats was very similar to the female rats and has been reported previously (Wiley and Lappi, 2003). Except where specifically indicated, male and female rats gave similar responses on the various tests and in response to Dermsap and morphine. All procedures were approved by the Vanderbilt University Institutional Animal Care and Use Committee and conformed to the National Institutes of Health Guide for the Care and Use of Laboratory Animals.

Lesioning MOR-expressing dorsal horn neurons. Derm-sap and blanksaporin (nonsense peptide-saporin conjugate) were supplied by Advanced Targeting Systems (San Diego, CA). The toxin was dissolved in sterile, preservative-free normal saline containing $1 \%$ bovine serum albumin and $0.1 \%$ Fast Green dye to permit visualization of injection volumes. This diluent has shown no neuropathological effects in rat brain (Book et al., 1995). Concentrated stock solutions were stored at $-20^{\circ} \mathrm{C}$. Working dilutions were made fresh, stored on ice until use the same day, and then discarded. For intrathecal injections, rats were anesthetized by intraperitoneal injections of a ketamine-xyalzine-acepromazine mixture supplemented with additional ketamine as needed to maintain insensibility. Lumbar intrathecal catheters (Recathco LLC, Allison Park, PA) were inserted into the spinal subarachnoid space through a small incision in the atlanto-occipital membrane as per the technique of Yaksh and Rudy (1976). The catheters were inserted to a depth of 8-8.5 $\mathrm{cm}$ from the dural incision. Toxin or saline vehicle was injected in a volume of $10 \mu \mathrm{l}$, followed by a $10 \mu \mathrm{l}$ flush of vehicle, and the catheters were removed $10 \mathrm{~min}$ later or secured immediately with sutures for chronic experiments. Wounds were closed with clips, and rats warmed until awake and then returned to home cages. After recovery from surgery, verification of chronically implanted lumbar catheters was determined by observing temporary hindlimb paralysis resulting from an intrathecal injection of $20 \mu \mathrm{l}(0.5 \%)$ of xylocaine-MPF. No histological abnormalities are produced after single lumbar intrathecal injections of
$2 \%$ lidocaine or $0.5 \%$ bupivacaine $(0.12 \mu \mathrm{l} / \mathrm{g}$ body weight $)$ in the rat (Takenami et al., 2005).

Anatomical procedures. Spinal cord sections were prepared as described previously (Vierck et al., 2003). Briefly, 2 weeks to 4 months after toxin or vehicle injections, rats were deeply anesthetized with sodium pentobarbital and perfused transcardially with $200-300 \mathrm{ml}$ of cold normal saline containing $5 \mathrm{~mm}$ sodium phosphate, $\mathrm{pH} 7.5,1 \mathrm{~g} / \mathrm{L}$ sodium nitrite (vasodilator), and $1000 \mathrm{U} / \mathrm{L}$ sodium heparin (anticoagulant), followed by $4 \%$ formaldehyde prepared from paraformaldehyde in $100 \mathrm{~mm}$ sodium phosphate, $\mathrm{pH}$ 7.5. Spinal cords and dorsal root ganglia (DRGs) were postfixed for at least $1 \mathrm{~h}$ and stored in fixative at $4^{\circ} \mathrm{C}$, until the day before sectioning, when spinal cord blocks and DRGs were equilibrated overnight in $30 \%$ sucrose in $5 \mathrm{~mm}$ sodium phosphate, $\mathrm{pH}$ 7.5. Transverse sections of the lumbosacral spinal cord were cut at $40 \mu \mathrm{m}$ thickness on a freezing sliding microtome (American Optical, Southbridge, MA). Bilateral L4 DRGs were frozen in embedding matrix (M-1, Pittsburgh, PA) sectioned on a cryostat at $16 \mu \mathrm{m}$. Groups of six consecutive sections were collected on slides (DRGs) or in each well of 24-well tissue culture plates containing Tris-buffered saline (cord sections). Sections were equilibrated with antifreeze solution consisting of glycerol-ethylene glycolphosphate buffer and stored at $-20^{\circ} \mathrm{C}$ until processed for immunohistochemistry for MOR1, MOR1C, and GIRK2.

Immunohistochemical procedures. Initially, one in six series of transverse spinal cord sections were removed from the antifreeze at room temperature and washed in Tris-buffered saline, followed by incubation for $1 \mathrm{~h}$ in $5 \%$ normal serum at room temperature. Then the free-floating sections were transferred to a primary antibody diluted in $1 \%$ serum and incubated overnight at $4^{\circ} \mathrm{C}$. The next day, sections were washed and processed for peroxidase immunohistochemistry using the standard biotin-avidin technique (ABC Elite kit; Vector Laboratories, Burlingame, CA) using diaminobenzidine/nickel as the chromogen. Two MOR antibodies were used in this study: a presynaptic and postsynaptic splice variant, MOR1 (Aicher et al., 2003) (Chemicon, Temecula, CA), and a predominately presynaptic splice variant, MOR1C (Abbadie et al., 2001) (generously provided by G. Pasternak, Sloan-Kettering Memorial Cancer Center, New York, NY). Rabbit anti-GIRK2 (Alamone Labs, Jerusalem, Israel) was used to stain postsynaptic dorsal horn potassium channels, which are found in either of two populations of superficial dorsal horn neurons: MOR expressing or $\mathrm{GABA}_{\mathrm{B}}$ receptor expressing (Marker et al., 2004, 2006). Reacted sections were washed and mounted on gelatincoated slides, dehydrated, cleared, and examined using a Lieca (Nussloch, Germany) DM 6000B photomicroscope. DRGs were always processed on slides in parallel to spinal cord sections. Vehicle control and Derm-sap sections were processed simultaneously in parallel using the same solutions and conditions. Additional sections from segments L4 and L5 were processed as needed to provide $8-10$ from these spinal levels.

MOR1, MOR1C, and GIRK2 measurements. As reported previously (Wiley et al., 2007), we used computer-assisted quantitative densitometry techniques to evaluate MOR1, MOR1C, and GIRK2 staining in the superficial dorsal horn. Using randomized coded sections to blind the operator to the experimental condition, user-defined areas of interest encompassing the entire mediolateral extent of laminas I and II were digitally captured using a Leica DM 6000B photomicroscope. Both right and left dorsal horns from 8 to 10 stained sections of lumbar segments L4 and L 5 were photographed. The $40 \%$ darkest pixels (intensity $0-100$ out of a range of 0-250 gray levels) were chosen as consistently representing specific staining after comparing the distribution of computer-selected stained pixels to visual inspection of the peroxidase-stained sections. Mean pixel counts for each rat were computed from the $8-10 \mathrm{~L} 4 / 5 \mathrm{sec}-$ tions measured from each rat. In addition, L4 DRGs were stained for MOR1C, and every sixth $16 \mu \mathrm{m}$ section was manually counted from coded slides to obtain the percentage of total neurons expressing MOR1C. Individual DRG means were averaged to obtain treatment group means.

Drugs. Preservative-free morphine sulfate sterile solution (Baxter, Deerfield, IL) was diluted in preservative-free sterile physiological saline for both systemic (subcutaneous) and intrathecal administration. Subcutaneous morphine $(0.0,2.5,5.0$, and $10.0 \mathrm{mg} / \mathrm{kg}$ ) was injected $20 \mathrm{~min}$ (or $30 \mathrm{~min}$ in the loperamide experiments) before hotplate testing. Thirty 
minutes before hotplate testing, intrathecal morphine $(0,0.01,0.1$, and $1.0 \mu \mathrm{g} / \mu \mathrm{l}$ ) was injected, followed immediately by an $8 \mu \mathrm{l}$ saline flush. Intrathecal injections of morphine, using a $10 \mu$ l Hamilton (Reno, NV) syringe, were made under brief isofluorane $(2 \%)$ anesthesia. Previous pilot testing showed that the antinociceptive effect of isofluorane in the $44^{\circ} \mathrm{C}$ hotplate test wore off within $20 \mathrm{~min}$. Loperamide ( $1 \mathrm{mg} / \mathrm{kg}$; Sigma, St. Louis, MO) was dissolved in 20\% cyclodextran (Sigma) and sterile saline for subcutaneous administration. In formalin experiments using systemic morphine (10 mg/kg, s.c.), the drug was injected $30 \mathrm{~min}$ before hindpaw formalin injection.

Behavioral testing. All behavioral testing was in a dedicated room with low-level illumination and white noise background. Each day rats were allowed to acclimate to the testing room for $30 \mathrm{~min}$ before behavioral testing began. For a $4 \mathrm{~d}$ systemic morphine dose-response curve at three hotplate temperatures, testing was conducted each Monday to Thursday for 3 weeks.

Tail flick. Standard nocifensive reflex tail flick testing was performed on Sprague Dawley rats using a radiant heat apparatus (IITC, Woodland Hills, CA). Rats were gently restrained in a ventilated Plexiglas tube (IITC) loosely covered with a towel and allowed to acclimate for 5-10 min before testing. For each daily session, 10 successive trials ( $60 \mathrm{~s}$ apart) with each rat were averaged to obtain a mean value for that day for each rat.

Hotplate procedures. A modified hotplate test, as described previously, was used to assess effects of depletion of MOR-expressing dorsal horn neurons on innate spinal brainstem-spinal nocifensive reflex responses to noxious thermal stimuli (Vierck et al., 2004). In brief, before any testing, rats were acclimated to the room temperature test chamber, which consisted of a clear Plexiglas box $(30 \times 30 \times 15 \mathrm{~cm})$ with a ventilated lid sitting on a custom-built aluminum plate containing internal circulation channels to assure uniform surface temperature. The temperature of the plate was controlled by a thermally regulated circulator [Polyscience (Warrington, PA) circulating bath model 9105] as described previously (Mauderli et al., 2000). Plate temperature was continuously monitored [YSI (Yellow Springs, OH) 4900 thermometer with contact thermistor probe attached to the floor plate]. Before each $44^{\circ} \mathrm{C}$ test trial, rats were placed in an identical enclosure with the floor temperature at $38^{\circ} \mathrm{C}$ for $10 \mathrm{~min}$ and then transferred to the test chamber. This procedure limits the rate that the plantar skin was heated to a maximum of $2.4^{\circ} \mathrm{C} / \mathrm{min}$ (Vierck et al., 2004). At $44^{\circ} \mathrm{C}$, each trial lasted $600 \mathrm{~s}$. At $47^{\circ} \mathrm{C}$, each trial was $200 \mathrm{~s}$, and at $52^{\circ} \mathrm{C}$, rats were removed shortly after the first nocifensive response or a maximum cutoff of $30 \mathrm{~s}$, whichever came first. For comparison of responses to different hotplate temperatures, initial response latencies were converted to percentage maximum possible effect $(\% \mathrm{MPE})$, where $\% \mathrm{MPE}=($ postdrug latency - postsaline latency $) \times$ $100 /$ (cutoff - postsaline latency). Hindpaw licking and guarding (sustained lifting) behaviors were captured in real time by continuous observation with the assistance of a custom-designed computer program that recorded latency and duration of each response as well as total numbers of responses and total amount of time spent responding. The lower temperatures $\left(44-47^{\circ} \mathrm{C}\right)$ allow observation of both latencies and durations of multiple responses (Vierck et al., 2002). Latency to first response, total number of responses, and total time spent responding (duration) were recorded at the end of each trial for each rat. We previously found that five daily trials are necessary to obtain stable baseline performance on the last three trials, which then were averaged to obtain pretreatment baselines.

Formalin test. Formalin observation boxes were located in a dimly lit room with sound-deadening and white background noise. These boxes were $30 \times 30 \times 30 \mathrm{~cm}$ with black walls and clear Plexiglas floors. On the test day, all rats were given injections of $25 \mu \mathrm{l}$ of $5 \%$ formaldehyde in sterile water using a Hamilton syringe with a 30 gauge, half-inch needle. Injections were subplantar. Each rat was tested only once and killed $2.5 \mathrm{~h}$ after injection. Immediately after injection, rats were placed in the observation cage that had a video camera located beneath the clear plastic floor. All behavior was videotaped for the next $85 \mathrm{~min}$. Off-line, tapes were reviewed by a rater unaware of the experimental condition. At $5 \mathrm{~min}$ intervals, behavior was rated for $1 \mathrm{~min}$, and these $1 \mathrm{~min}$ interval ratings were plotted against time for each rat. As described previously (Gau- mond et al., 2005), phase I was defined as the first 9 min after injection, interphase was defined as minutes 9-21, and phase II was defined as 21-90 minutes after. Data included both the amount of time spent in licking, lifting (guarding), and biting/licking the injected foot and the number of such responses.

Statistical procedures. Raw anatomical data, stained pixel counts (spinal cord sections), or percentage of positive neurons (DRGs) as described above were compared primarily using one-way ANOVA techniques with a minimum significance level of $p<0.05$ to reject the null hypothesis using SigmaStat software (SPSS, Chicago, IL). The Tukey's test was used for pairwise comparisons within the ANOVA analysis. The above procedures are similar to those described previously (Wiley et al., 2007). Linear regression analysis and product-moment correlation coefficients were calculated for analysis of interrelationships between variables, particularly doses of morphine versus hotplate behavior. For raw behavioral data (number of nocifensive responses, duration of nocifensive or escape responding, etc.), similar techniques were used including $t$ test and repeated-measures ANOVA (two and three way).

\section{Results}

\section{Dorsal horn anatomy}

As reported previously (Aicher et al., 2000; Abbadie et al., 2001), MOR1 is expressed on both dorsal horn neurons and presynaptic terminals in laminas I and II (Fig. $1 A$ ). The density of dorsal horn MOR1 (Fig. $1 B$ ) staining was significantly reduced by $\sim 34 \%$ $(p=0.01 ; F=7.2 ; \mathrm{df}=1$; one-way ANOVA $)$ after lumbar intrathecal Derm-sap [500 ng, intrathecal (i.t.)]. Loss of dorsal horn MOR1 was predominately medial in lamina II (Fig. $1 B$ ), in agreement with our previous reports (Wiley and Lappi, 2003). Specific staining for the C-terminus splice variant of the $\mu$-opioid receptor MOR1C appeared as thin-beaded processes in laminas I and II (Abbadie et al., 2001) (Fig. 1D). Dorsal horn staining for MOR1C splice variant did not differ between PBS- or Derm-saptreated rats $(p>0.05)$ (Fig. $1 E, F)$. These data indicate that lumbar intrathecal Derm-sap selectively destroyed dorsal horn neurons expressing MOR1, rather than primary afferent neurons expressing MOR1C. Immunoreactivity for GIRK2, a key signal transduction molecule associated with postsynaptic action of MOR (Marker et al., 2004), was dense in laminas I-II and decorated some processes in laminas III-V and X (Fig. $1 G$ ). The density of GIRK2 staining in medial laminas I-II was reduced after Derm-sap treatment ( $p=0.03 ; F=5.0 ; \mathrm{df}=1$; one-way ANOVA) (Fig. $1 H$ ). Based on previous observations in our laboratory, we found that $500 \mathrm{ng}$ in a $10 \mu \mathrm{l}$ lumbar intrathecal injection of Derm-sap alters dorsal horn MOR staining intensity only within the lumbar enlargement, but not more rostrally. Any toxin not receptor bound is subject to prompt degradation by neutral endopeptidases, at the doses used in these experiments. Lumbar intrathecal nonconjugated saporin (Rahman et al., 2007; Vera-Portocarrero et al., 2007) or blank-saporin (Abe et al., 2005) had no measurable anatomical or behavioral effects, an observation previously confirmed on numerous occasions in our laboratory for intrathecal saporin doses $\leq 500 \mathrm{ng}$. To confirm the lack of effect of lumbar intrathecal unconjugated saporin, we determined the effects of lumbar intrathecal saporin on dorsal horn MOR staining. Lumbar enlargements from saporin-treated (1000 ng, i.t.; $n=3)$ or PBS-treated $(n=3)$ rats were sectioned and stained for MOR (Chemicon) 2 months after injection. Dorsal horn L4 MOR staining in saporin-injected rats was $100.18 \pm$ $10 \%$ (SEM) of PBS-injected rats; thus, we conclude there was not a significant effect of saporin on dorsal horn MOR staining ( $p=$ 0.98 , two-tailed $t$ test). 

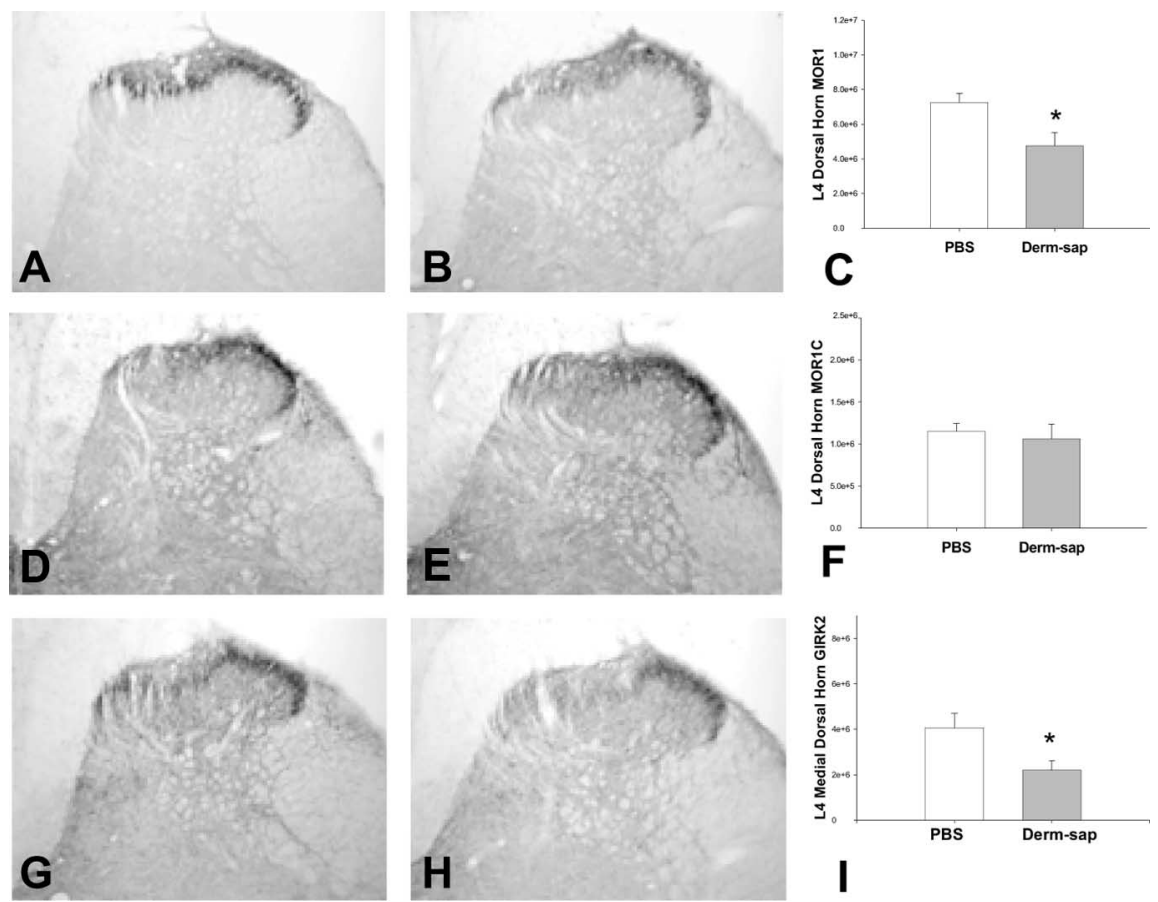

Figure 1. Anatomic effects of intrathecal Derm-sap as illustrated by representative photomicrographs of lumbar enlargement dorsal horn sections. $\boldsymbol{A}, \boldsymbol{B}$, Sections were stained for MOR1 $30 \mathrm{~d}$ after lumbar intrathecal PBS $(\boldsymbol{A})$ or $500 \mathrm{ng}$ of Derm-sap $(\boldsymbol{B})$ in Long-Evans female rats. Note the decreased intensity of staining in lamina II after Derm-sap. $\boldsymbol{D}, \boldsymbol{E}$, Unlike MOR1, no changes in MOR1C staining were observed after intrathecal PBS (D) or Derm-sap $(\boldsymbol{E})$ in the same rats. $\boldsymbol{G}, \boldsymbol{H}$, Derm-sap $(\boldsymbol{H})$ shows decreased GIRK2 staining compared with PBS $(\boldsymbol{G})$, most striking medially, in the same rats. $C, F, I$, Bar graphs representing densitometry of L4 dorsal horn staining for MOR1 $\left(\boldsymbol{C} ;{ }^{*} p<0.05\right.$, one-way ANOVA) and MOR1C $(\boldsymbol{F})$ and GIRK2 $(I)\left({ }^{*} p<0.05\right.$, one-way ANOVA). $\mathrm{PBS}, n=10$; Derm-sap, $n=9$. Results are expressed as mean \pm SEM.

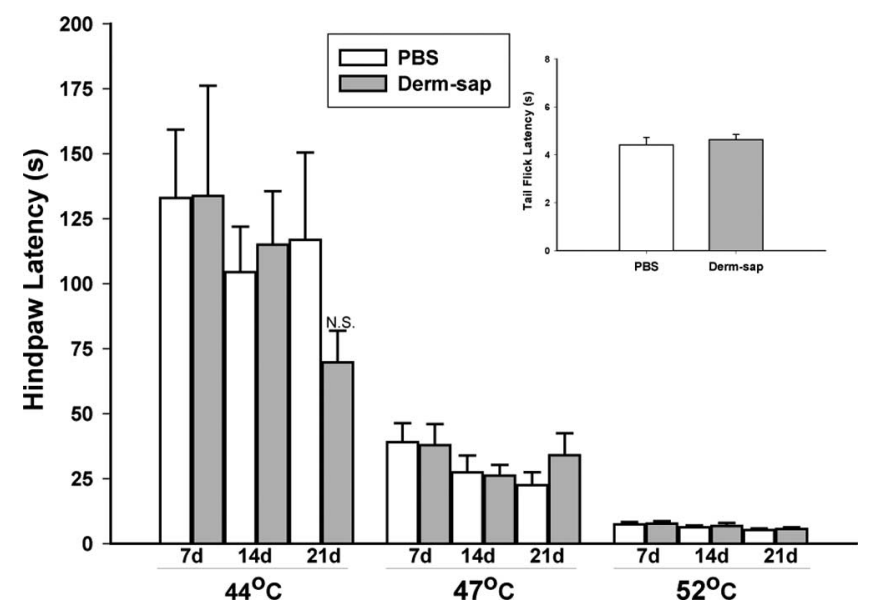

Figure 2. Lack of effect of Derm-sap on baseline sensitivity to noxious heat. Hotplate latencies 7,14 , and $21 \mathrm{~d}$ after lumbar intrathecal PBS ( $n=8$ ) or Derm-sap ( $500 \mathrm{ng} ; n=8)$ on 44, 47, and $52^{\circ} \mathrm{C}$ hotplates in Sprague Dawley male rats. At each hotplate temperature, latencies to the first response did not differ between the PBS control and Derm-sap-injected groups from either preinjection baseline (data not shown) or between treatment groups at any temperature. Comparison of latencies across hotplate temperatures was significantly different $(p<0.001$, Tukey's test). Tail-flick responses were unaffected $39-40 \mathrm{~d}$ after intrathecal Derm-sap. Inset, Results are expressed as mean \pm SEM. N.S., Not significant.

\section{DRGs}

To further assess the effects of Derm-sap on primary afferent nociceptors, we stained L4 DRGs for MOR1C (Abbadie et al., 2001), 2 months after toxin injection. There was no significant difference in the percentage of MOR1C-positive cell bodies after
PBS $(n=4 ; 21.4 \pm 1.66 \%$ SD) or Dermsap $(n=4 ; 20.89 \pm 1.34 \% \mathrm{SD})(p=0.61$; $\mathrm{df}=4 ; t$ test $)$. Therefore, we conclude that $500 \mathrm{ng}$ of lumbar intrathecal Derm-sap does not effectively kill DRG cells expressing MOR.

It is not known precisely why intrathecal Derm-sap does not affect MOR1Cexpressing DRG neurons. Possible explanations include the possibility that primary afferent terminals in the superficial dorsal horn do not endocytose Derm-sap, that larger doses of Derm-sap are required to kill DRG neurons, or even if taken up, that the toxin is not retrogradely transported to cell bodies. We are not aware of any additional data on uptake of peptide-saporin conjugates by presynaptic axon terminals. In any case, the observations listed above clearly show that under the conditions used in these studies, DRG neurons were not killed by $500 \mathrm{ng}$ lumbar intrathecal injections of Derm-sap.

\section{Baseline thermal nocifensive reflex responses}

To determine the effect of Derm-sap on baseline nocifensive reflex responses to noxious thermal stimuli, we assessed hotplate responses at 44,47 , and $52^{\circ} \mathrm{C}$ up to $21 \mathrm{~d}$ after lumbar intrathecal Derm-sap injections. No significant changes in baseline hotplate responses were evident after Derm-sap or PBS (Fig. 2). Similarly, tail-flick responses were also unaffected at $30 \mathrm{~d}$ after intrathecal Derm-sap (Fig. 2, inset). To determine any effects of saporin alone on nocifensive reflex behavior, we compared $44^{\circ} \mathrm{C}$ hotplate responses 1 week after $500 \mathrm{ng}$ of lumbar intrathecal blank-saporin conjugate $(n=3)$ or PBS $(n=3)$. The latency to the first hindpaw lick/guard response did not differ between blank-sap $(197.3 \pm 67.5$ SEM $)$ or PBS $(163.6 \pm 22.6$ SEM $)(p=$ $0.66, t$ test). The present findings indicate Derm-sap produces no long-term $(>7 \mathrm{~d})$ alteration in baseline nocifensive reflex sensitivity to noxious thermal stimuli.

\section{Intrathecal morphine}

Intrathecal administration of morphine $(0.01,0.1$, and $1.0 \mu \mathrm{g})$ to normal rats resulted in a significant increase in initial hindpaw lick/guard latency ( $p=0.004 ; F=6.37$; $\mathrm{df}=3$; two-way ANOVA) and a decrease in the number of nocifensive responses during the $600 \mathrm{~s}, 44^{\circ} \mathrm{C}$ hotplate test $(p=0.006 ; F=8.83$; df $=3$; two-way ANOVA) (Fig. 3). After Derm-sap treatment, however, morphine was less effective in increasing hindpaw latency in the same rats $(p>0.05 ; F=0.61 ; \mathrm{df}=3$; two-way ANOVA $)$ and did not reduce total nocifensive reflex response duration in the same rats $\left(p>0.05 ; F=0.61 ; \mathrm{df}=3\right.$; two-way ANOVA). The $44^{\circ} \mathrm{C}$ hotplate hindpaw latencies after intrathecal saline injection were not significantly different when compared before and after Derm-sap ( $p=0.23, t$ test). Additionally, the postsaline $44^{\circ} \mathrm{C}$ hotplate total hindpaw lick/guard durations were not different when compared before and after Derm-sap ( $p=0.48, t$ test). Latencies to the first response at $52^{\circ} \mathrm{C}$ were significantly and equally elevated in both groups $30 \mathrm{~min}$ after intrathecal morphine only at the $10 \mu \mathrm{g}$ dose (Fig. 4$)(p=0.001 ; F=39.26$; $\mathrm{df}=$ 

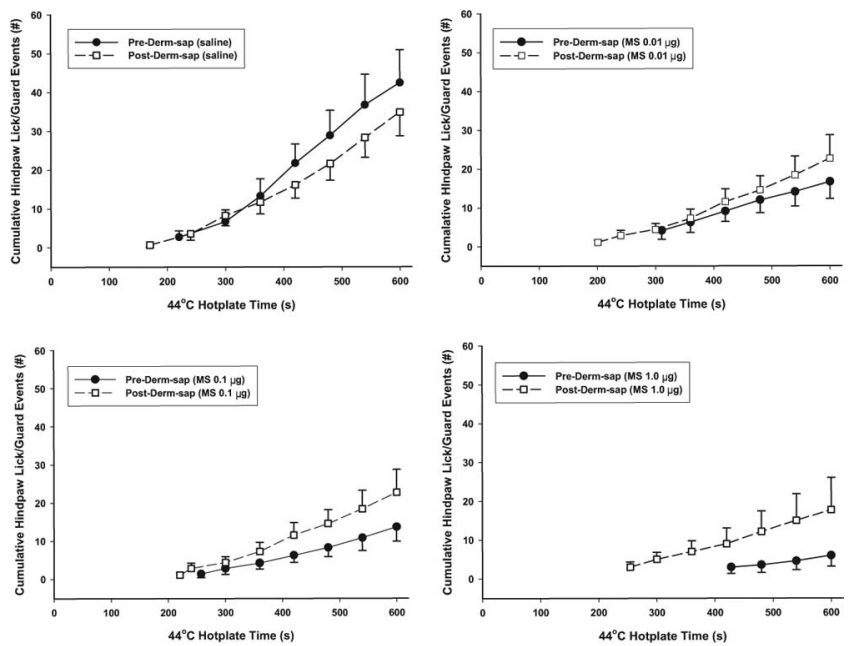

Figure 3. Effects of intrathecal morphine on hotplate responding at $44^{\circ} \mathrm{C}$. The number of hindpaw lick/guard responses $30 \mathrm{~min}$ after intrathecal morphine was recorded during the $44^{\circ} \mathrm{C}$ hotplate test (600 s trial duration) $4 \mathrm{~d}$ before and 8-11 d after lumbar intrathecal Derm-sap $(500 \mathrm{ng})$. Each curve begins at the average first latency and shows the cumulative total number of withdrawal responses. Comparing Pre-Derm-sap versus Post-Derm-sap, neither latencies ( $p=0.23, t$ test) nor total response durations ( $p=0.48, t$ test) was significantly different. These experiments used Long-Evans female rats $(n=7)$ with indwelling intrathecal catheters. Morphine dose-dependently reduced the number of hindpaw responses during the $44^{\circ} \mathrm{C}$ hotplate test before (two-way repeated-measures ANOVA; $p=0.006 ; F=8.83 ; \mathrm{df}=3$ ) but not after ( $p>0.05 ; F=0.56 ; \mathrm{df}=3$ ) Derm-sap. Similarly, morphine dose-dependently prolonged the latency to the first hindpaw withdrawal response before (two-way repeatedmeasures ANOVA; $p=0.004 ; F=6.37 ; \mathrm{df}=3$ ) but not after Derm-sap $(p=0.67 ; F=0.51$; $\mathrm{df}=3$ ). Results are expressed as mean \pm SEM.

2; two-way ANOVA). To determine any effects of chronic catheterization of the lumbar intrathecal space, we compared hotplate responses at 44 and $52^{\circ} \mathrm{C}$ in Long-Evans female rats, five naive and five with intrathecal catheters for $30 \mathrm{~d}$; no change in nocifensive responding sensitivity was observed at either temperature. Hindpaw first lick/guard latencies at $44^{\circ} \mathrm{C}$ were $127.1 \pm$ $25.36 \mathrm{~s}$ (SEM) for catheterized rats and $108.2 \pm 22.34 \mathrm{~s}$ (SEM) for naive rats ( $p=0.57, t$ test). Hindpaw first lick/guard latencies at $52^{\circ} \mathrm{C}$ were $6.96 \pm 1.22$ SEM for catheterized rats and $7.46 \pm .46$ SEM for naive rats $(p=0.71, t$ test $)$.

\section{Systemic $\boldsymbol{\mu}$-opioid agonists}

Dose-response curves for subcutaneous morphine on 44,47 , and $52^{\circ} \mathrm{C}$ hotplates showed full antinociceptive activity in animals with previous intrathecal PBS injections but reduced potency in intrathecal Derm-sap animals (Fig. 5). Although morphine did increase hindpaw latencies in Derm-sap animals at 44 and $47^{\circ} \mathrm{C}$, the antinociceptive effect was only significant at $10.0 \mathrm{mg} / \mathrm{kg}(p=$ 0.02, Tukey's test) (Fig. 5). On the $52^{\circ} \mathrm{C}$ hotplate, subcutaneous morphine failed to produce a dose-related effect on hotplate responses at any dose in Derm-sap-treated rats $(r=0.03 ; p=0.99$; $\mathrm{df}=3$; ANOVA) compared with a significant effect in PBStreated rats $(r=0.57 ; p=0.04 ; \mathrm{df}=3$; ANOVA). In both PBS control and Derm-sap-treated rats, and as reported previously in normal rats (Vierck et al., 2002), morphine (2.5 mg/kg, s.c.) paradoxically increased hindpaw lick/guard response duration on the $44^{\circ} \mathrm{C}$ hotplate $(p=0.01 ; F=7.74 ; \mathrm{df}=1$; two-way ANOVA). The total response duration, time spent licking or lifting a hindpaw, during the $600 \mathrm{~s}$ trials at $44^{\circ} \mathrm{C}$ and during the $200 \mathrm{~s}$ trials at $47^{\circ} \mathrm{C}$ stimulation was reduced in both groups (PBS and Dermsap) by morphine at 5.0 and $10.0 \mathrm{mg} / \mathrm{kg}(p=0.001 ; F=26.7$; $\mathrm{df}=3$; three-way ANOVA) compared with the $2.5 \mathrm{mg} / \mathrm{kg}$ dose.

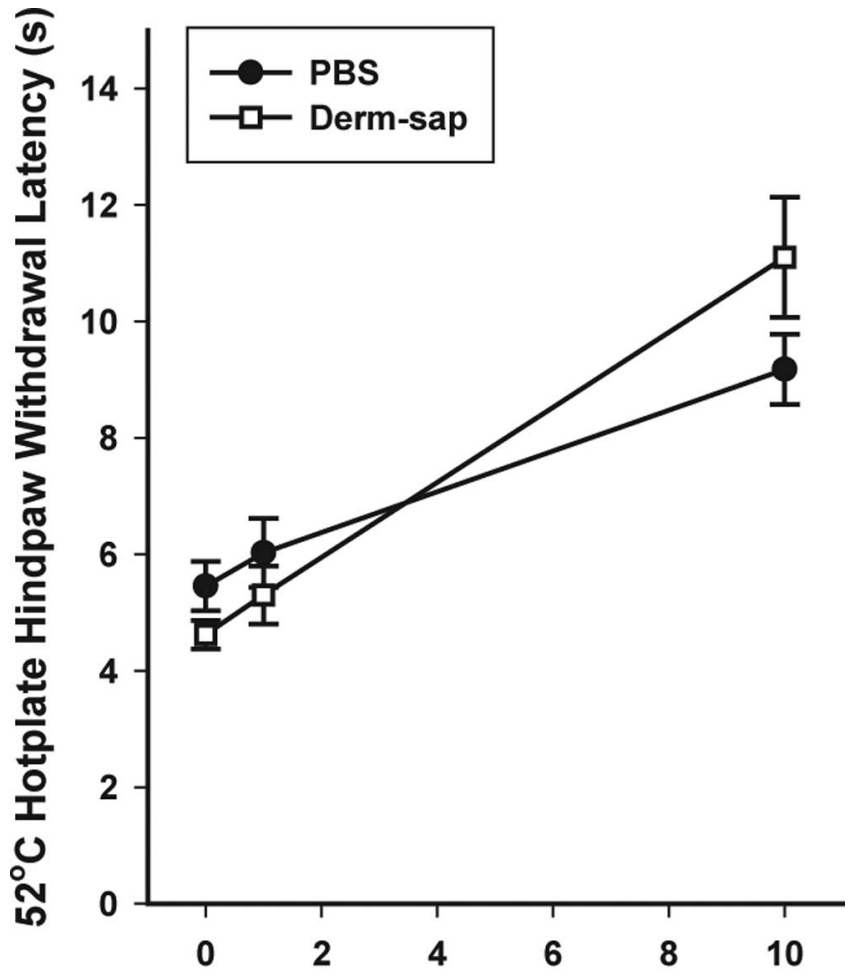

i.t. Dose of Morphine $(\mu \mathrm{g})$

Figure 4. The $52^{\circ} \mathrm{C}$ hotplate $30 \mathrm{~min}$ after intrathecal (i.t.) morphine. Hindpaw withdrawal latencies $9-11 \mathrm{~d}$ after lumbar intrathecal PBS $(n=6)$ or Derm-sap $(500 \mathrm{ng} ; n=6)$ in LongEvans female rats. Morphine significantly increased hotplate hindpaw withdrawal latencies after either PBS or Derm-sap at the $10 \mu \mathrm{g}$ dose ( $p=0.001$ ); however, the $1 \mu \mathrm{g}$ dose was not different from saline (two-way ANOVA; $p=0.57 ; F=39.26 ; \mathrm{df}=2$ ). The difference between PBS and Derm-sap at $10 \mu \mathrm{g}$ was not significant. Results are expressed as mean \pm SEM.

However, the antinociceptive effects of systemic morphine were significantly greater in PBS controls than in Derm-sap-treated rats at 44 and $47^{\circ} \mathrm{C}(p=0.001)$ by Tukey's test (Fig. 6). To determine whether lumbar intrathecal injection of saporin alone alters the antinociceptive effects of systemic morphine, intrathecal blank-saporin-injected rats ( $500 \mathrm{ng} ; n=3$ ) or intrathecal PBS $(n=3)$-treated rats were given injections of morphine $(7.5 \mathrm{mg} /$ $\mathrm{kg}$, s.c.) or saline $20 \mathrm{~min}$ before hotplate testing at $44^{\circ} \mathrm{C}$. Systemic morphine significantly reduced hotplate responding by $20 \%$ after blank-saporin and by $22.5 \%$ after PBS ( $p=0.79, t$ test) $10-11 \mathrm{~d}$ after lumbar intrathecal injection. To further assess whether lumbar intrathecal Derm-sap affected primary afferents, we compared the effects of the peripherally acting $\mu$-opiate agonist loperamide, on $44^{\circ} \mathrm{C}$ hotplate responses in rats previously injected intrathecally with Derm-sap or PBS. Systemic loperamide (1 mg/ $\mathrm{kg}$ ) was equally effective in reducing $44^{\circ} \mathrm{C}$ hotplate nocifensive reflex responses in rats previously treated with lumbar intrathecal PBS or Derm-sap ( $p=0.001 ; F=919.2$; df $=2$; two-way ANOVA) (Fig. 7). In contrast, systemic morphine was less effective in the same Derm-sap-treated rats ( $p=0.004$, Tukey's test $)$ (Fig. 6).

\section{Formalin test}

The formalin test elicits persistent nocifensive behavior that has been shown sensitive to opiates (Morgan et al., 2006). We compared the behavioral responses to subcutaneous injection of $25 \mu \mathrm{l}$ (5\%) of formalin into one hindpaw in Derm-sap and PBS control 

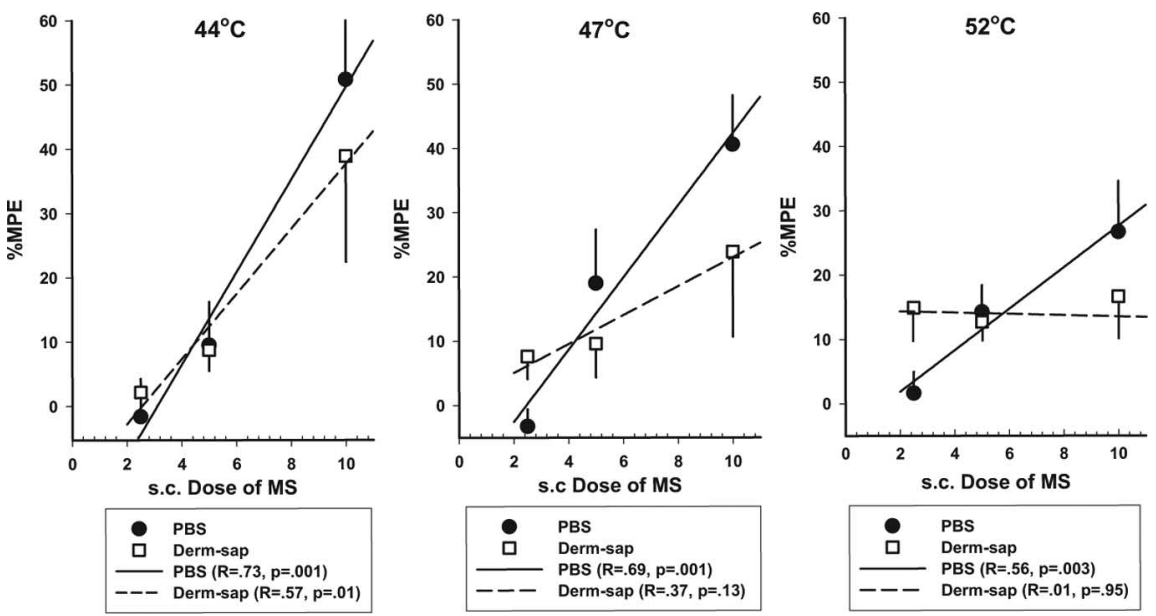

Figure 5. Effects of systemic morphine on hindpaw withdrawal latencies on the hotplates. Dose-response curves in Sprague Dawley male rats show the effect [percentage maximum possible effect (\%MPE)] of subcutaneous morphine $(0,2.5,5.0$, and 10 $\mathrm{mg} / \mathrm{kg} 20 \mathrm{~min}$ before testing) on hindpaw latencies $21-38 \mathrm{~d}$ after lumbar intrathecal PBS $(n=8)$ or Derm-sap ( $500 \mathrm{ng} ; n=7)$ on 44,47 , and $52^{\circ} \mathrm{C}$ hotplate. Morphine prolonged hindpaw latencies in PBS control animals in a dose-related manner at all three hotplate temperatures (two-way repeated-measures ANOVA; $p<0.001 ; F=26.21$; $\mathrm{df}=2$ ). All pairwise comparisons for morphine dose were significantly different in PBS rats ( $p<0.001$, Tukey's test), but not after Derm-sap treatment ( $p=0.09$, Tukey's test). Correlation coefficients and significance values (ANOVA) for morphine dose-response curves are also indicated for each hotplate temperature. Results are expressed as mean \pm SEM. Derm-sap treatment significantly reduced the antinociceptive potency of morphine at 44 and $47^{\circ} \mathrm{C}$.

rats. To insure there were no gender- or time-dependent effects of Derm-sap in the formalin test, male rats were tested at 3 months and female rats were tested at 1 month after lumbar intrathecal Derm-sap or PBS. Both groups showed the typical biphasic nocifensive response curve lasting $90 \mathrm{~min}$ in control rats (Gaumond et al., 2005). Derm-sap-treated male rats spent more time licking/ biting the injected hindpaw during the interphase and phase II of the formalin test than PBS controls (two-way ANOVA; $F=$ 46.73; $\mathrm{df}=1 ; p<0.001$ ) (Fig. $8 A$ ) three months after toxin injection. Similarly, in female rats, the total number of hindpaw events (lick/guard/bite) also were greater during both phases I and II ( $p=0.001$, Tukey's test) (Fig. $8 B$ ) of the formalin test performed 1 month after Derm-sap injection. Interphase behavior for female rats was increased, but not significantly ( $p=0.09$, Tukey's test). In an additional group of female rats, reductions in nocifensive responses by systemic morphine $(10 \mathrm{mg} / \mathrm{kg}$, s.c.; 30 min prior) in the formalin test were greater in PBS animals compared with Derm-sap rats 1 month after toxin injection (two-way ANOVA; $F=32.67$; $\mathrm{df}=1 ; p<0.002$ ) (Fig. 9), consistent with the reduced effect of morphine in Derm-sap-treated rats.

\section{Discussion}

The present study shows that lumbar intrathecal injection of Derm-sap produced (1) partially decreased staining for MOR1 and GIRK2 but not MOR1C in the superficial dorsal horn of the lumbar spinal cord; (2) a profoundly decreased antinociceptive effect of intrathecal morphine in the hotplate test; (3) a significantly reduced antinociceptive effect of systemic morphine, but not systemic loperamide, in the hotplate test; (4) increased nocifensive behavior in the hindpaw formalin test; and (5) a reduced antinociceptive effect of morphine in the formalin test. We interpret these findings as indicating that dorsal horn MORexpressing neurons are necessary for full antinociceptive action of intrathecal morphine, for some of the antinociceptive action of systemic morphine and these neurons may be involved in modulation of nocifensive reflex responses to persistent noxious chemical stimulation.
The observation that lumbar intrathecal Derm-sap selectively reduced MOR1, but not MOR1C, staining indicates Dermsap selectively destroys lamina II MORexpressing neurons but not MOR1Cexpressing primary afferents. Also in support of predominant selectivity of lumbar intrathecal Derm-sap for dorsal horn MOR1-expressing neurons, as opposed to primarily DRG MOR1C-expressing neurons, is the observation that expression of MOR1C-like mRNA occurred in very "few cells" in the rat lumbar superficial dorsal horn compared with very "many small and large cells" in the DRGs (Schnell and Wessendorf, 2004). Three other observations in the present study support the selective dorsal horn lesion by Derm-sap: (1) counts of MOR1C-expressing L4 DRG primary afferent cell bodies were not significantly different between control and Derm-sap rats; (2) Derm-sap did not produce a significant change in baseline nocifensive reflex responding on the hotplate and tail flick tests, suggesting that primary afferent thermal nociceptors were intact; and (3) the antinociceptive effect of the peripherally restricted $\mu$-opiate loperamide was unaffected by Derm-sap, also suggesting primary afferents were intact. We have previously reported (Wiley and Lappi, 2005) two observations that further support the conclusion that intrathecal Derm-sap does not damage primary afferent neurons: (1) cell counts from lumbar DRGs taken 24-96 h after $750 \mathrm{ng}$ of intrathecal Derm-sap failed to reveal any evidence of the typical acute, severe chromatolysis produced by saporin; and (2) assessment of MOR staining from rats with multilevel lumbar dorsal rhizotomies in the absence or presence of intrathecal Derm-sap showed that rhizotomies or Derm-sap alone each produced $\sim 50 \%$ loss of MOR staining in the superficial lumbar dorsal horn, but combining rhizotomies and Derm-sap completely abolished MOR staining in the dorsal horn consistent with two separate cellular pools of dorsal horn MOR, primary afferent terminals, and lamina II interneurons (Aicher et al., 2000; Abbadie et al., 2002). Because lumbar intrathecal injections of substance $\mathrm{P}$-saporin conjugate have no effect on morphine antinociception in the same hotplate protocols used in the present study (Vierck et al., 2003), we conclude the observed effects of Derm-sap on morphine antinociception are specific for this conjugate and not a common property of all lumbar intrathecal peptide-saporin conjugate injections. We estimate the observed $34 \%$ decrease actually represents $\sim 68 \%$ loss of dorsal horn postsynaptic MOR1, because about half of all MOR1 staining is presynaptic on primary afferent terminals (i.e., lost after rhizotomy) (Wiley and Lappi, 2005).

Based on the well known expression of MOR on C fiber primary afferent terminals (Lamotte et al., 1976; Aicher et al., 2000) and the preferential antinociceptive effect of morphine on $\mathrm{C}$ fiber-mediated pain ( $\mathrm{Lu}$ et al., 1997), we had anticipated that selective loss of MOR-expressing interneurons might not affect the antinociceptive effect of intrathecal morphine in the $44^{\circ} \mathrm{C}$ hotplate test, which elicits $\mathrm{C}$ nociceptor-mediated nocifensive reflex responses (Vierck et al., 2004). Because our anatomic observations (above) indicate that DRG neurons and their central terminals were unaffected by lumbar intrathecal Derm-sap and 
$\mathrm{A}-44^{\circ} \mathrm{C}$
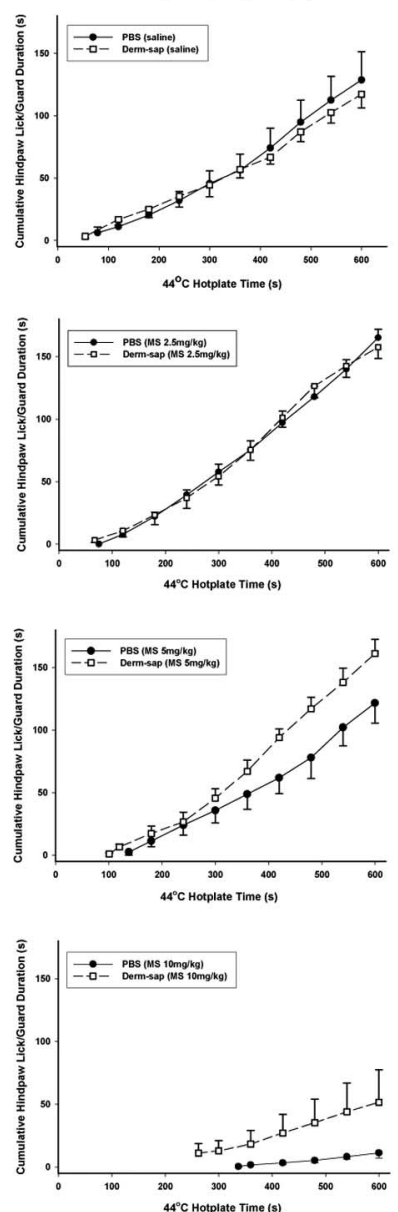

$\mathrm{B}-47^{\circ} \mathrm{C}$
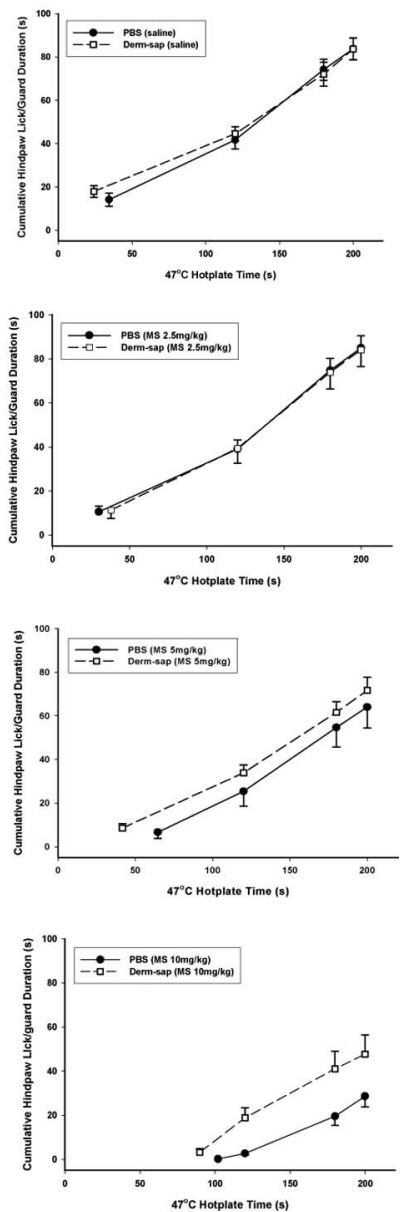

Figure 6. The $44^{\circ} \mathrm{C}$ and $47^{\circ} \mathrm{C}$ hotplate responses $20 \mathrm{~min}$ after systemic morphine. Comparisons of morphine dose-related effects on hindpaw lick/guard durations on the $44^{\circ} \mathrm{C}(600 \mathrm{~s}$ trial duration; $\boldsymbol{A}$ ) and $47^{\circ} \mathrm{C}$ ( 200 s trial duration; $\boldsymbol{B}$ ) hotplate tests $21-31 \mathrm{~d}$ after lumbar intrathecal $\operatorname{PBS}(n=7)$ or Derm-sap ( $500 \mathrm{ng} ; n=6)$ in Sprague Dawley male rats. Each curve begins at the average first latency and shows the cumulative total duration of withdrawal responses. Lowdose systemic morphine $(2.5 \mathrm{mg} / \mathrm{kg})$ increased hindpaw lick/guard responding on the $44^{\circ} \mathrm{C}$ hotplate in both PBS- and Derm-sap-injected groups (three-way ANOVA; $p=0.001 ; F=26.7$; $\mathrm{df}=3$ ). Compared with saline and the $2.5 \mathrm{mg} / \mathrm{kg}$ dose, systemic morphine reduced hindpaw lick/guard responding on the $44^{\circ} \mathrm{C}$ hotplate in PBS controls and in the Derm-sap-injected group at $5.0 \mathrm{mg} / \mathrm{kg}$ and at $10 \mathrm{mg} / \mathrm{kg}$ (three-way ANOVA; $p=0.001 ; F=26.7 ; \mathrm{df}=3$ ). Similarly, at $47^{\circ} \mathrm{C}$ morphine decreased hindpaw lick/guard responding at 5 and $10 \mathrm{mg} / \mathrm{kg}$ in both PBS- and Derm-sap-injected groups ( $p=0.001 ; F=22.0 ; \mathrm{df}=3$; three-way ANOVA). Comparison of PBS controls and Derm-sap rats at 5 and $10 \mathrm{mg} / \mathrm{kg}$ morphine on both temperatures revealed that the antinociceptive effect was greater in PBS control rats than in the Derm-sap-injected group ( $p=0.001$, Tukey's test). Results are expressed as mean \pm SEM.

the behavioral data show decreased morphine antinociception in Derm-sap-treated rats, we interpret the present results as calling into question the hypothesis that morphine acts by inhibiting primary afferent terminals (Aimone and Yaksh, 1989; Ueda et al., 1995; Kondo et al., 2005). One difference between the present study and experiments that showed morphine inhibition of evoked spinal glutamate (Ibuki et al., 2003) and substance P release (Gu et al., 2005) is the use of high-intensity stimuli in the release experiments that would be expected to activate $\mathrm{A} \delta$ primary afferents. Also, the release experiments did not identify the cellular source of the glutamate and substance P. Further doubt about the importance of $\mu$-opiate effects on primary afferent terminals comes from the observations that (1) internalization of MOR into dorsal horn neurons in response to $\mu$-opiate agonists
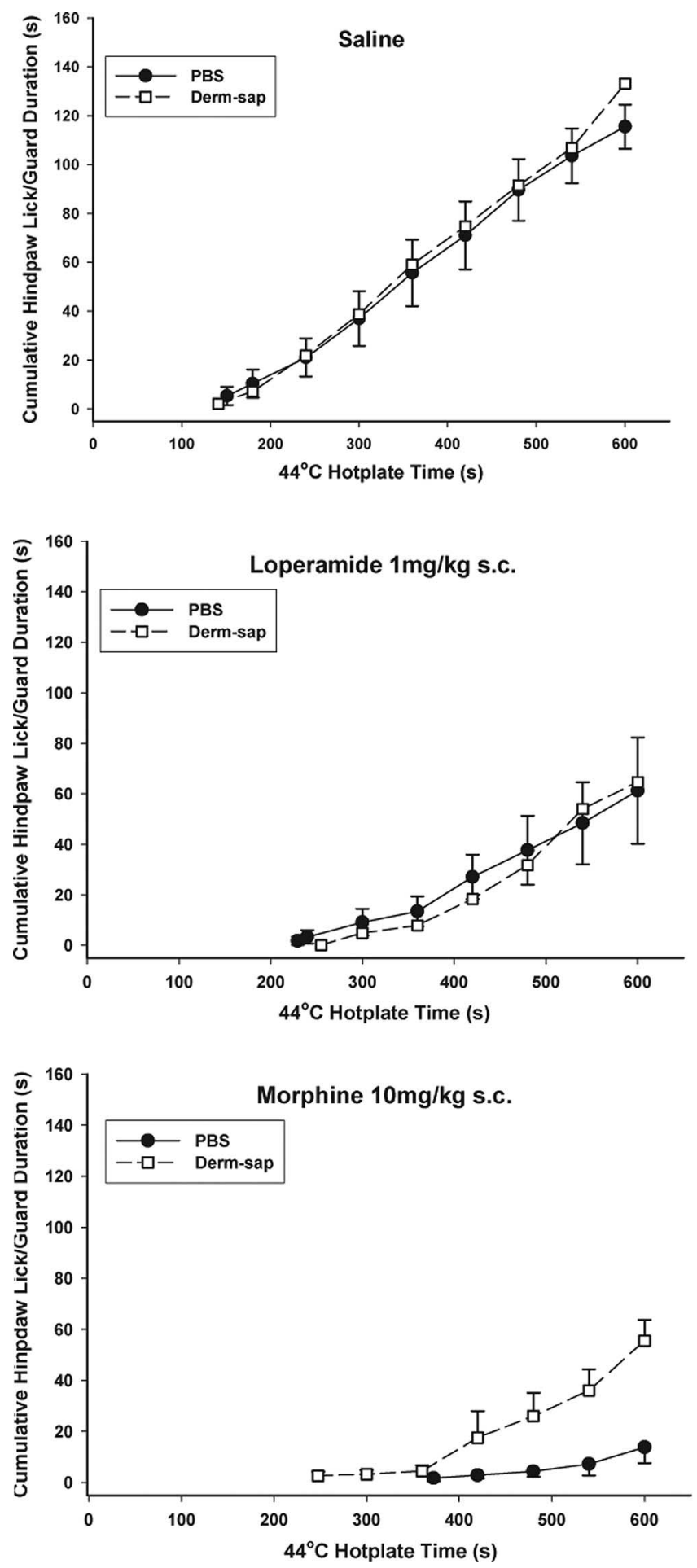

Figure 7. Comparison of morphine and loperamide on the $44^{\circ} \mathrm{C}$ hotplate. Total hindpaw lick/guard durations are shown after subcutaneous saline, loperamide $(1 \mathrm{mg} / \mathrm{kg})$, or morphine $(10 \mathrm{mg} / \mathrm{kg})$ injected $30 \mathrm{~min}$ before a $44^{\circ} \mathrm{C}$ hotplate test (600 s trial duration) in Long-Evans female rats $24-27 \mathrm{~d}$ after lumbar intrathecal PBS $(n=6)$ or Derm-sap ( $500 \mathrm{ng} n=6)$. Each curve begins at the average first latency and shows the cumulative total duration of withdrawal responses. The peripherally restricted $\mu$-opioid agonist loperamide significantly reduced hindpaw lick/guard durations in both intrathecal PBS and Derm-sap rats to the same degree compared with subcutaneous saline (two-way ANOVA; $p<0.001 ; F=14.4 ; \mathrm{df}=2$ ). Subcutaneous morphine also decreased hotplate responses in both PBS control and Derm-sap groups compared with loperamide ( $p<0.001 ; F=5.56 ; \mathrm{df}=2$; two-way ANOVA), but subcutaneous morphine produced significantly greater antinociception in PBS controls compared with the Derm-sap-injected group ( $p=0.004$, Tukey's test). Each curve begins at the average first latency. Results are expressed as mean \pm SEM. 

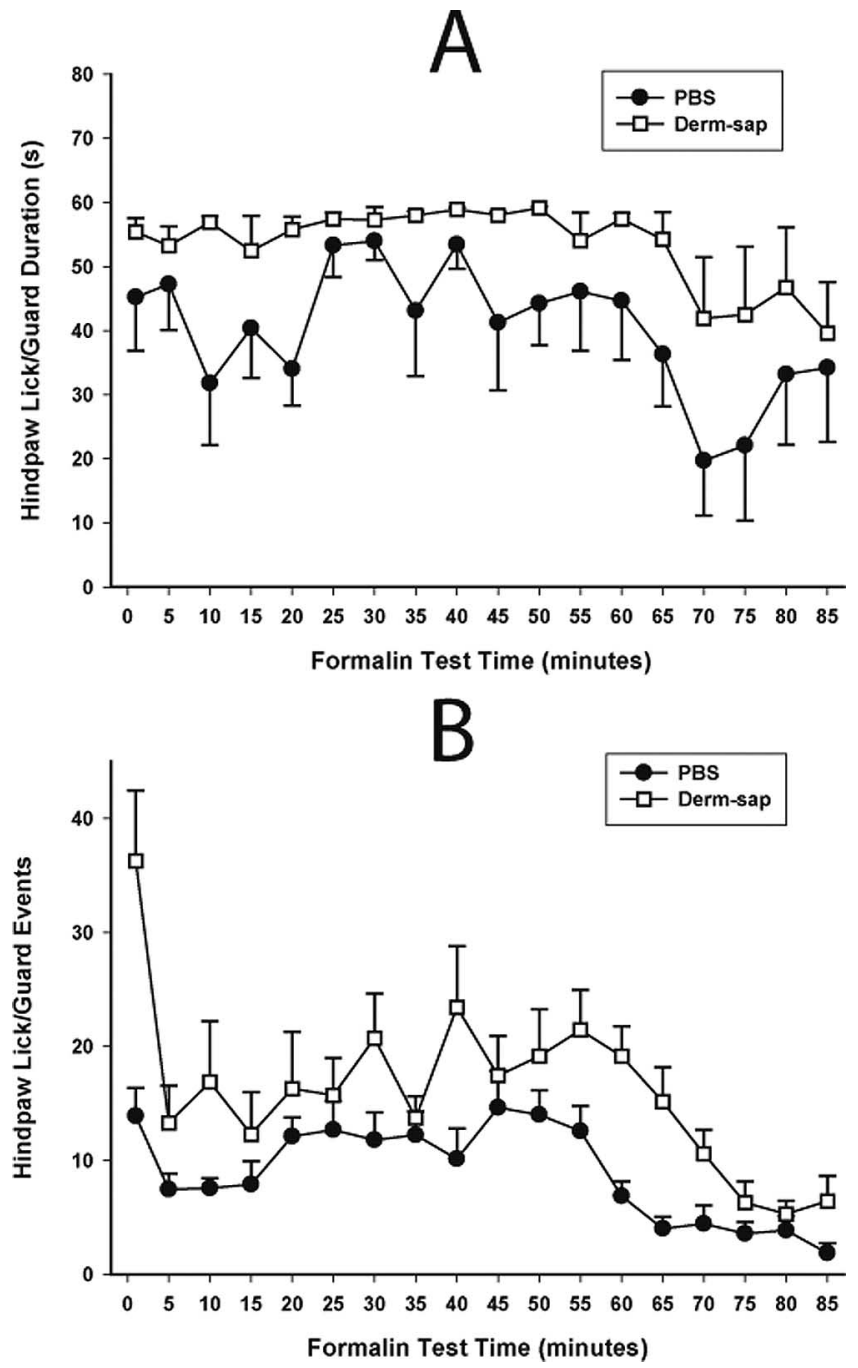

Figure 8. Derm-sap effects on formalin responding. $\boldsymbol{A}$, Effects of a $25 \mu \mathrm{l}$ plantar formalin (5\%) injection into one hindpaw on time spent licking or guarding (durations) 3 months after lumbar intrathecal PBS $(n=6)$ or Derm-sap (500 ng $n=6)$ in Sprague Dawley male rats. $\boldsymbol{B}$, Derm-sap increased the total amount of formalin-induced hindpaw licking and guarding behavior in the interphase and phase ll periods (two-way ANOVA; $p<0.001 ; F=46.73 ; \mathrm{df}=1$ ). Similarly, using the same dose of formalin in Long-Evans female rats $30 \mathrm{~d}$ after lumbar intrathecal Derm-sap ( $500 \mathrm{ng} ; n=7)$, Derm-sap rats showed an increased total number of hindpaw lick/guard events during phases I and II compared with PBS rats $(n=7)$ (two-way ANOVA; $p<$ $0.002 ; F=32.67 ; \mathrm{df}=1$ ). Differences in interphase for this group were not significant $(p=$ 0.07). Results are expressed as mean \pm SEM.

correlates with increased hotplate latencies (Trafton et al., 2000; Trafton and Basbaum, 2004) and (2) 80\% of noxious stimulusinduced neurokinin-1 receptor internalization into superficial dorsal horn neurons persists despite treatment with $\mu$-opiate agonists (Trafton et al., 1999), consistent with intact release of substance $\mathrm{P}$ from primary afferents. Those observations plus the present study raise the possibility that the reduced evoked spinal release of glutamate and substance $\mathrm{P}$ may primarily reflect postsynaptic actions of $\mu$-opiate agonists.

The reduction in antinociceptive effects of systemic morphine in lumbar intrathecal Derm-sap-treated rats is consistent with reports that spinal intrathecal $\mu$-opiate antagonists reduce the antinociceptive effects of systemic morphine administration (Mjanger and Yaksh, 1991; Chen and Pan, 2006) and suggests that a dorsal horn site is necessary for the full antinociceptive effect of systemic $\mu$-opiate agonists. However, significant nocif-

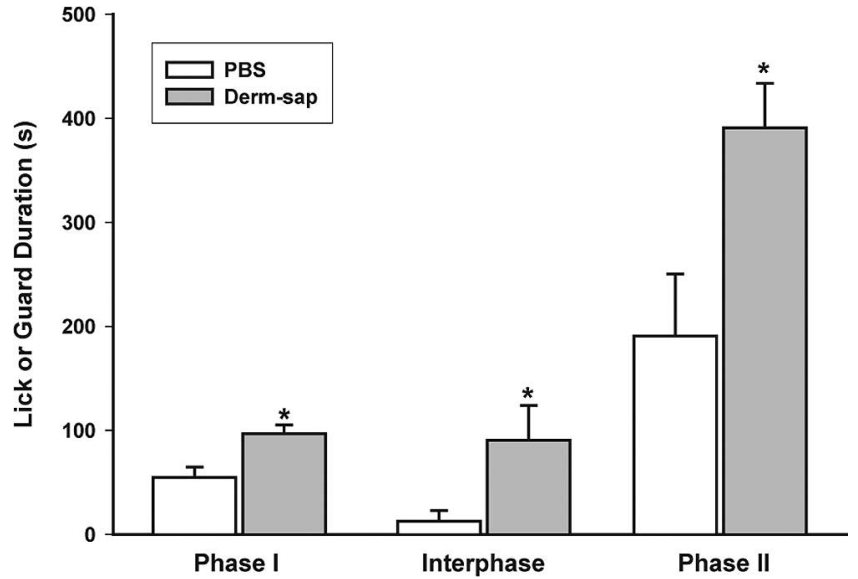

Figure 9. Effects of Derm-sap on morphine antinociception in the formalin test. The effects of a $25 \mu \mathrm{l}$ plantar injection of formalin (5\%) on hindpaw behavior in Long-Evans female rats $30 \mathrm{~d}$ after lumbar intrathecal PBS $(n=6)$ or Derm-sap ( $500 \mathrm{ng} ; n=4)$ pretreated with morphine ( $10 \mathrm{mg} / \mathrm{kg}$, s.c.) $30 \mathrm{~min}$ before formalin. Formalin behaviors are expressed by phase: phase I, 0-9 min; interphase, 9-21 min; phase Il, 21-90 min. Morphine was significantly less effective in reducing the total amount of hindpaw licking and guarding in Derm-sap rats (twoway ANOVA; $\left.{ }^{*} p=0.001 ; F=13.17 ; \mathrm{df}=1\right)$. Error bars represent means \pm SEM.

ensive reflex responses remained present under systemic morphine in Derm-sap-treated rats and also in the reports of intrathecal antagonists, suggesting at least one additional, probably supraspinal site for antinociceptive action of systemically administered $\mu$-opiate agonists (South and Smith, 1998; Gilbert and Franklin, 2002) that ultimately may not involve the MORexpressing dorsal horn destroyed by Derm-sap.

Increased nocifensive responding in Derm-sap-treated rats in the formalin test shows that loss of dorsal horn MOR-expressing neurons has long-lasting effects on modulation of nocifensive responses. Specifically, we hypothesize that increased responding during interphase and phase II of the formalin test produced by Derm-sap reflects reduction in the reported active inhibition of nocifensive responding that occurs during the interphase and phase II (Henry et al., 1999). The decreased antinociceptive effect of morphine in the formalin test produced by Derm-sap further supports the generality of the previous conclusion from hotplate data that dorsal horn MOR-expressing neurons play an important role in the antinociceptive action of systemic morphine. Transgenic mice lacking MOR expression have been reported to have some abnormalities of nocifensive behavior (increased interphase or phase II behavior) in the formalin test (Martin et al., 2003; Zhao et al., 2003), and so have mice with defective postsynaptic signaling by the MOR receptor because of lack of expression of GIRK2 (Mitrovic et al., 2003). Mice lacking GIRK2 also show decreased morphine effect in the formalin test. As reported above, Derm-sap decreased dorsal horn staining for GIRK2, presumably because of loss of the MOR-expressing dorsal horn neurons that also express GIRK2. The report that GIRK2-expressing lamina II dorsal horn neurons receive abundant $\mathrm{C}$ afferent input (Marker et al., 2006) correlates well with the present observation that Derm-sap destruction of the MOR/GIRK2 dorsal horn neurons more effectively reduced intrathecal morphine effects on nocifensive reflex behavior in the $44^{\circ} \mathrm{C}$ hotplate test, had somewhat less effect at $47^{\circ} \mathrm{C}$, but had no effect on morphine antinociception in the $52^{\circ} \mathrm{C}$ hotplate test.

We note that the effects of Derm-sap in the present study are similar to the behavioral and pharmacological effects of lesions to the dorsolateral funiculus (dlf) (Abbott et al., 1996) that (1) do 
not change baseline thermal nocifensive reflex responses in the tail immersion test, (2) reduce the effect of morphine in the tail immersion test, (3) increase nocifensive responses in the formalin test, and (4) reduce the effect of morphine in the formalin test. A unifying hypothesis to explain these similarities in the effects of dlf lesions and Derm-sap would be that inhibitory modulation of nocifensive reflexes in response to tonic noxious stimulation involves a descending pathway contained in the dlf that acts via lamina II MOR-expressing dorsal horn interneurons to preferentially reduce responses to $\mathrm{C}$ primary afferent nociceptor input. Thus, the lamina II MOR-expressing dorsal horn neurons emerge as important to both endogenous opioid-mediated antinociception and as a site for antinociceptive action of exogenous $\mu$-opiate agonists. Future studies of Derm-sap in operant algesia tests may clarify the relevance of the present findings to morphine analgesia.

\section{Conclusion}

The present study demonstrates that intrathecal injection of Derm-sap can produce a selective lesion of dorsal horn MORexpressing neurons and that this lesion reduces the effect of intrathecal morphine on nocifensive reflex responding to phasic noxious thermal stimuli, partially reduces the effect of systemic morphine on responses to both low-intensity phasic thermal and tonic chemical noxious stimuli, and increases nocifensive responding in response to tonic chemical nociceptive stimuli. These results indicate an important role for the dorsal horn MOR-expressing neurons in both the antinociceptive action of exogenous $\mu$-opiates and in endogenous nocifensive reflex modulation and also suggests dorsal horn MOR-expressing neurons may be fruitful targets for novel analgesic strategies.

\section{References}

Abbadie C, Pasternak GW, Aicher SA (2001) Presynaptic localization of the carboxy-terminus epitopes of the mu opioid receptor splice variants MOR-1C and MOR-1D in the superficial laminae of the rat spinal cord. Neuroscience 106:833-842.

Abbadie C, Lombard MC, Besson JM, Trafton JA, Basbaum AI (2002) Mu and delta opioid receptor-like immunoreactivity in the cervical spinal cord of the rat after dorsal rhizotomy or neonatal capsaicin: an analysis of pre- and postsynaptic receptor distributions. Brain Res 930:150-162.

Abbott FV, Hong Y, Franklin KB (1996) The effect of lesions of the dorsolateral funiculus on formalin pain and morphine analgesia: a doseresponse analysis. Pain 65:17-23.

Abe T, Ohsita N, Sugiyo M, Moritani M, Kobayashi M, Takemura M (2005) Elimination of neurokinin-1 receptor neurons in caudal nucleus reverses the effects of systemic bicuculline onc-fos expression in rat trigeminal sensory nucleus. Neuroscience 133:739-747.

Aicher SA, Sharma S, Chehng PY, Liu-Chen LY, Pcikel VM (2000) Dual ultrastructural localization of mu-opiate receptors and substance $P$ in the dorsal horn. Synapse 36:12-20.

Aicher SA, Mitchell JL, Swanson KC, Zadina JE (2003) Endomorphin-2 axon terminals contact mu-opioid receptor-containing dendrites in trigeminal dorsal horn. Brain Res 977:190-198.

Aimone LD, Yaksh TL (1989) Opioid modulation of capsaicin-evoked release of substance $\mathrm{P}$ from rat spinal cord in vivo. Peptides 10:1127-1131.

Book AA, Wiley RG, Schweitzer JB (1995) Neuropathology in the rat brain. Acta Neuropathol 89:519-526.

Chen SR, Pan HL (2006) Blocking mu opioid receptors in the spinal cord prevents the analgesic action by subsequent systemic opioids. Brain Res 1081:119-125.

Cooper BY, Vierck Jr CJ, Yeomans DC (1986) Selective reduction of second pain sensations by systemic morphine in humans. Pain 24:93-116.

Gaumond I, Arsenault P, Marchand S (2005) Specificity of female and male sex hormones on excitatory and inhibitory phases of formalin-induced nociceptive responses. Brain Res 1052:105-111.

Gilbert AK, Franklin KB (2002) The role of descending fibers from the ros- tral ventromedial medulla in opioid analgesia in rats. Eur J Pharmacol 449:75-84

Gu G, Kondo I, Hua XY, Yaksh TL (2005) Resting and evoked spinal substance $P$ release during chronic intrathecal morphine infusion: parallels with tolerance and dependence. J Pharmacol Exp Ther 314:1362-1369.

Henry JL, Yashpal K, Pitcher GM, Coderre TJ (1999) Physiological evidence that the "interphase" in the formalin test is due to active inhibition. Pain 82:57-63.

Hernandez A, Contreras E, Paeile C, Perez H, Pelissier T, Quijada L, SotoMoyano R (1993) Calcium channel modulators modify K opioidinduced inhibition of C-fiber-evoked spinal reflexes in rat. Int J Neurosci 72:167-174.

Ibuki T, Marsala M, Masuyama T, Yaksh TL (2003) Spinal amino acid release and repeated withdrawal in spinal morphine tolerant rats. Br J Pharmacol 138:689-697.

Kondo I, Marvizon JC, Song B, Salgado F, Codeluppi S, Hua XY, Yaksh TL (2005) Inhibition by spinal $\mu$ - and $\delta$-opioid agonists of afferent-evoked substance P release. J Neurosci 25:3651-3660.

Lamotte C, Pert CB, Snyder SH (1976) Opiate receptor binding in primate spinal cord: distribution and changes after dorsal root section. Brain Res 112:407-412.

Light AR, Perl ER (1979) Reexamination of the dorsal root projection to the spinal dorsal horn including observations on the differential termination of coarse and fine fibers. J Comp Neurol 186:117-131.

Lu Y, Pirec V, Yeomans DC (1997) Differential antinociceptive effects of spinal opioids on foot withdrawal responses evoked by $\mathrm{C}$ fibre or A delta nociceptor activation. Br J Pharmacol 121:1210-1216.

Marker CL, Stoffel M, Wickman K (2004) Spinal G-protein-gated K ${ }^{+}$channels formed by GIRK1 and GIRK2 subunits modulate thermal nociception and contribute to morphine analgesia. J Neurosci 24:2806-2812.

Marker CL, Lujan R, Colon J, Wickman K (2006) Distinct populations of spinal cord lamina II interneurons expressing G-protein-gated potassium channels. J Neurosci 26:12251-12259.

Martin M, Matifas A, Maldonado R, Kieffer BL (2003) Acute antinociceptive responses in single and combinatorial opioid receptor knockout mice: distinct mu, delta and kappa tones. Eur J Neurosci 17:701-708.

Mauderli AP, Acost-Rua A, Vierck Jr CJ (2000) An operant assay of thermal pain in conscious, unrestrained rats. J Neurosci Methods 97:19-29.

Mitrovic I, Margeta-Mitrovic M, Bader S, Stoffel M, Jan LY, Basbaum AI (2003) Contribution of GIRK2-mediated postsynaptic signaling to opiate and alpha 2-adrenergic analgesia and analgesic sex differences. Proc Natl Acad Sci USA 100:271-276.

Mjanger E, Yaksh TL (1991) Characteristics of dose-dependent antagonism by beta-funaltrexamine of the antinociceptive effects of intrathecal mu agonists. J Pharmacol Exp Ther 258:544-550.

Morgan MM, Fossum EN, Stalding BM, King MM (2006) Morphine antinociceptive potency on chemical, mechanical, and thermal nociception tests in the rat. J Pain 7:358-366.

Moriwaki A, Wang JB, Svingoa A, van Bosckstaele E, Cheng P, Pickle V, Uhl GR (1996) Mu opiate receptor immunoreactivity in rat central nervous system. Neurochem Res 21:1315-1331.

Porreca F, Burgess SE, Gardell LR, Vanderah TW, Malan Jr TP, Ossipov MH, Lappi DA, Lai J (2001) Inhibition of neuropathic pain by selective ablation of brainstem medullary cells expressing the $\mu$-opioid receptor. J Neurosci 21:5281-5288.

Rahman W, Sikander S, Suzuki R, Hunt SP, Dickenson AH (2007) Superficial NK1 expressing spinal dorsal horn neurons modulate inhibitory neurotransmission mediated by spinal GABA(A) receptors. Neurosci Lett 419:278-283.

Schnell SA, Wessendorf MW (2004) Expression of MOR1C-like mu-opioid receptor mRNA in rats. J Comp Neurol 473:213-232.

South SM, Smith MT (1998) Apparent insensitivity of the hotplate latency test for detection of antinociception following intraperitoneal, intravenous or intracerebroventricular M6G administration to rats. J Pharmacol Exp Ther 286:1326-1332.

Stevens CW, Yaksh TL (1986) Spinal action of dermorphin, an extremely potent opioid peptide from frog skin. Brain Res 385:300-304.

Takenami T, Yagishita S, Murase S, Hiruma H, Kawakami T, Hoka S (2005) Neurotoxicity of intrathecally administered bupivicaine involves the posterior roots/posterior white matter and is less than lidocaine in rats. Reg Anesth Pain Med 30:464-472.

Trafton JA, Basbaum AI (2004) [d-Ala2,N-MePhe4,Gly-ol5] enkephalin- 
induced internalization of the micro opioid receptor in the spinal cord of morphine tolerant rats. Neuroscience 125:541-543.

Trafton JA, Abbadie C, Marchand S, Mantyh PW, Basbaum AI (1999) Spinal opioid analgesia: how critical is the regulation of substance $\mathrm{P}$ signaling? J Neurosci 19:9642-9653.

Trafton JA, Abbadie C, Marek K, Basbaum AI (2000) Postsynaptic signaling via the $\mu$-opioid receptor: responses of dorsal horn neurons to exogenous opioids and noxious stimulation. J Neurosci 20:8578-8584.

Ueda M, Sugimoto K, Oyama T, Kuraishi Y, Satoh M (1995) Opioidergic inhibition of capsaicin-evoked release of glutamate from rat spinal dorsal horn slices. Neuropharmacology 34:303-308.

Vera-Portocarrero L, Zhang E, King T, Ossipov M, Vanderah T, Lai J, Porreca F (2007) Spinal NK-1 receptor expressing neurons mediate opioidinduced hyperalgesia and antinociceptive tolerance via activation of descending pathways. Pain 129:35-45.

Vierck Jr CJ, Acosta-Rua A, Nelligan R, Tester N, Mauderli A (2002) Low dose systemic morphine attenuates operant escape but facilitates innate reflex responses to thermal stimulation. J Pain 3:309-319.

Vierck Jr CJ, Kline RH IV, Wiley RG (2003) Intrathecal substance P-saporin attenuates operant escape from nociceptive stimuli. Neuroscience 119:223-232.

Vierck Jr CJ, Kline IV RH, Wiley RG (2004) Comparison of operant escape and innate reflex responses to nociceptive skin temperatures produced by heat and cold stimulation of rats. Behav Neurosci 118:627-635.
Wiley RG, Lappi, DA (2003) Targeted toxins in pain. Adv Drug Deliv Rev 55:1043-1054.

Wiley RG, Lappi DA (2005) Saporin conjugates and pain. In: Molecular neurosurgery with targeted toxins (Wiley RG, Lappi DA, eds), pp 235248. Totowa, NJ: Humana.

Wiley RG, Kline IV RH, Vierck CJ (2007) Anti-nociceptive effects of selectively destroying substance $\mathrm{P}$ receptor expressing dorsal horn neurons using $\left[\operatorname{Sar}^{9}, \operatorname{Met}\left(\mathrm{O}_{2}\right)^{11}\right]$-substance P-saporin: behavioral and anatomical analyses. Neuroscience 146:1333-1345.

Yaksh TL, Rudy TA (1976) Chronic catheterization of the spinal subarachnoid space. Physiol Behav 17:1031-1036.

Yeomans DC, Proudfit HK (1996) Nociceptive responses to high and low rates of noxious cutaneous heating are mediated by different nociceptors in the rat: electrophysiological evidence. Pain 68:141-150.

Yeomans DC, Cooper BY, Vierck Jr CJ (1996) Effects of systemic morphine on responses of primates to first or second pain sensations. Pain 66:253-263.

Zhang RX, Wang L, Liu B, Qiao JT, Ren K, Berman BM, Lao L (2005) Mu opioid receptor-containing neurons mediate electroacupunctureproduced anti-hyperalgesia in rats with hind paw inflammation. Brain Res 1048:235-240.

Zhao CS, Tao YX, Tall JM, Donovan DM, Meyer RA, Raja SN (2003) Role of mu-opioid receptors in formalin-induced pain behavior in mice. Exp Neurol 184:839-845. 